\title{
Integrasi Pertanian, Kehutanan, dan Peternakan (Agrosilvopastural) di Wilayah DAS Laeya Kabupaten Konawe Selatan
}

\author{
Deki Zulkarnain $^{1 *}$, Kahirun ${ }^{2}$, Mukhtar ${ }^{3}$, Abdi $^{3}$, La Ode Jabuddin ${ }^{3}$ \\ ${ }^{1}$ Dosen Tetap Fakultas Peternakan Universitas Halu Oleo, Kendari \\ ${ }^{2}$ Dosen Tetap Fakultas Kehutanan Universitas Halu Oleo, Kendari \\ ${ }^{3}$ Dosen Tetap Fakultas Pertanian Universitas Halu Oleo, Kendari \\ Jl. H.E.A. Mokodompit Kampus Hijau Bumi Tridharma, Anduonohu, Kendari 93232 \\ *Email korespndensi: deki.zulkarnain75@gmail.com
}

(Diterima: 05-12-2018; disetujui 10-1-2019)

\begin{abstract}
ABSTRAK
Konsep agrosilvopastural merupakan salah satu komponen dari konsep agroforestri, yakni pengkombinasian antara komponen pertanian dengan kehutanan dan peternakan/hewan. Penelitian ini bertujuan untuk: (1) mengidentifikasi jenis usaha agrosilvopastural, (2) menganalisis karakteristik pelaku usaha agrosilvopastural dan (3) menganalisis keragaan usaha agrosilvopastural di wilayah sekitar DAS Laeya. Responden dalam penelitian ini adalah masyarakat yang bermukim di wilayah hulu dan hilir DAS Laeya dengan jumlah 51 rumah tangga. Analisis yang digunakan dalam kajian ini analisis deskriptif, pendapatan, analisis R/C-ratio. Hasil penelitian menunjukkan bahwa: Jenis usaha agrosilvopastural di wilayah sekitar DAS Laeya Kabupaten Konawe Selatan meliputi; (a) Tanaman pangan, palawija, dan hortikultura (semusim), yang terdiri dari; padi ladang, padi sawah, jagung, cabai, serta jenis sayur-sayuran dan buah-buahan, (b) Tanaman perkebunan (tahunan) yang terdiri dari; jambu mete, lada, dan kelapa sawit, (c) Tanaman kehutanan yang terdiri dari; jati lokal, jati putih, jabon, dan kayu biti, dan (d) Peternakan yang terdiri dari; sapi bali, unggas lokal, dan kambing. Berdasarkan hasil analisis $\mathrm{R} / \mathrm{C}$ ratio dan $\mathrm{B} / \mathrm{C}$ ratio, bahwa usaha agrosilvopastural di wilayah hulu dan hilir DAS Laeya Kabupaten Konawe Selatan layak untuk dijadikan sebagai objek pengembangan usaha agrosivopastural, dengan rata-rata nilai $\mathrm{R} / \mathrm{C}$ ratio sebesar 4,02 dan $\mathrm{B} / \mathrm{C}$ ratio sebesar 3,02.
\end{abstract}

Kata kunci: integrasi pertanian, kehutanan, peternakan

\begin{abstract}
The agrosilvopastural concept is one component of the concept of agroforestry, namely the combination of agricultural components with forestry and livestock / animal. This study aims to: (1) identify the type of agrosilvopastural business, (2) analyze the characteristics of agrosilvopastural business actors and (3) analyze the performance of agrosilvopastural businesses in the area around the Laeya watershed. Respondents in this study were people living in the upstream and downstream areas of the Laeya watershed with a total of 51 households. The analysis used in this study was descriptive analysis, income, R/C-ratio analysis. The results showed that: Types of agrosilvopastural businesses in the area around the Laeya watershed in South Konawe Regency include; (a) Food crops, secondary crops and horticulture (annuals), which consist of; field rice, paddy rice, corn, chili, and types of vegetables and fruits, (b) Plantation crops (annual) consisting of; cashew, pepper, and oil palm, (c) Forestry plants consisting of; local teak, white teak, jabon, and biti wood, and (d) Livestock consisting of; Bali cattle, local poultry, and goats. Based on the results of the $/ \mathrm{C}$ ratio and $\mathrm{B} / \mathrm{C}$ ratio, that the agrosilvopastural effort in the upstream and downstream areas of the Laeya watershed in Konawe Selatan Regency is feasible to be used as an object of developing agro-ventricural enterprises, with an average $\mathrm{R} / \mathrm{C}$ ratio of 4.02 and $\mathrm{B} / \mathrm{C}$ ratio of 3.02 .
\end{abstract}

Keywords: integration of agriculture, forestry. livestock 


\section{PENDAHULUAN}

Konsep agrosilvopastural merupakan salah satu komponen dari konsep agroforestri, yakni pengkombinasian antara komponen pertanian dengan kehutanan dan peternakan/hewan. Sebagaimana pemanfaatan lahan lainnya, agrosilvopastural dikembangkan untuk memberi manfaat kepada manusia atau meningkatkan kesejahteraan masyarakat. Agrosilvopastural diharapkan dapat memecahkan berbagai masalah pengembangan pedesaan dan seringkali sifatnya mendesak. Agrosilvopastural utamanya diharapkan dapat membantu mengoptimalkan hasil suatu bentuk penggunaan lahan secara berkelanjutan guna menjamin dan memperbaiki kebutuhan hidup masyarakat. Sistem berkelanjutan ini dicirikan antara lain oleh tidak adanya penurunan produksi tanaman dari waktu ke waktu dan tidak adanya pencemaran lingkungan. Kondisi tersebut merupakan refleksi dari adanya konservasi sumber daya alam yang optimal oleh sistem penggunaan lahan yang diadopsi (Direktorat Jenderal BPDASPS, 2005).

Dalam praktiknya, pemanfaatan luas lahan yang terbatas memberikan inovasi-inovasi pola yang secara bebas memberikan ruang pilihan kepada petani. Pola agroforestri-tumpangsari menggunakan jenis-jenis yang mempunyai prospek pasar yang menjanjikan (Sabarnurdin et al. 2011) petani memiliki tujuan menanam, yaitu: petani memperoleh manfaat sosial dari tumpangsari tanaman semusim seperti jagung, singkong, pisang, serta rumput gajah bagi petani yang memelihara ternak; manfaat ekonomi berupa hasil kayu untuk industri dengan pemasaran lokal maupun ekspor. Salah satu alternatif sistem penggunaan lahan untuk tujuan produksi dan konservasi adalah sistem agroforestri, yaitu pengelolaan komoditas pertanian, peternakan dan atau perikanan dengan komoditas kehutanan berupa pohon-pohonan. Agroforestri merupakan salah satu sistem pengelolaan lahan hutan dengan tujuan untuk mengurangi kegiatan perusakan/perambahan hutan sekaligus meningkatkan penghasilan petani secara berkelanjutan (Hairiah et al., 2000 dan de Foresta et el., 2000).

Untuk mewujudkan sasaran ini, agrosilvopastural diharapkan lebih banyak memanfaatkan tenaga ataupun sumber daya sendiri (internal) dibandingkan sumber-sumber dari luar. Di samping itu juga diharapkan dapat meningkatkan daya dukung ekologi manusia, khususnya di daerah pedesaan yang bermukim pada wilayah-wilayah sekitar daerah aliran sungai (DAS). Harapan sesungguhnya bahwa para pemangku kepentingan dapat secara bersama-sama dengan masyarakat lokal melakukan pengeloaan lahan pada DAS secara bijak, agar keberlangsungan hidup seluruh ekosistem dapat terus berjalan.

Konsep pengelolaan DAS hendaklah berpedoman pada satu sungai, satu perencanaan, dan satu pengelolaan. Dalam implementasinya merupakan tanggung jawab semua daerah di wilayah DAS tersebut. Pengaturan tataguna tanah di DAS dengan menetapkan luasan hutan minimum 30\% dari luas DAS merupakan satu langkah dalam menanggulangi banjir dan longsor, disamping upaya-upaya konservasi yang lainnya. Hutan mempunyai peran sangat penting dalam menahan aliran permukaan (run-off) yang sangat sinifikan mengurangi terjadinya banjir dan longsor (Atmojo, 2008).

Pengelolaan DAS bertujuan untuk mewujudkan kesadaran, kemampuan dan partisipasi aktif lembaga terkait dan masyarakat dalam pengelolaan DAS yang lebih baik, mewujudkan kondisi lahan yang produktif sesuai dengan daya dukung dan daya tampung lingkungan DAS secara berkelanjutan, mewujudkan kuantitas, kualitas dan berkelanjutan ketersediaan air yang optimal menurut ruang dan waktu mewujudkan peningakatan kesejahteraan masyarakat. Terbitnya Peraturan Pemerintah Nomor 37 tahun 2012 tentang Pengelolaan DAS menjadi Landasan hukum bagi penyelenggara pengelolaan DAS untuk mengkoordinasikan Pengelolaan DAS dalam rangka meningkatkan daya dukung DAS. Pengelolaan DAS diselenggarakan melalui perencanaan, pelaksanaan, peran serta dan pemberdayaan masyarakat, pendanaan, monitoring dan evaluasi, pembinaan dan pengawasan serta mendayagunakan sistem informasi pengelolaan DAS.

Wilayah DAS Laeya mencakup Kabupaten Konawe selatan yang menyebar di sepuluh Kecamatan yaitu Kecamatan Baito, Kecamatan Kolono, Kecamatan Konda, Kecamatan Laeya, Kecamatan Lainea, Kecamatan Moramo, Kecamatan Moramo Utara, Kecamatan Palangga, Kecamatan Palangga Selatan, Kecamatan Wolasi. Secara keseluruhan Wilayah DAS Laeya terbagi dalam beberapa wilayah Sub DAS yakni Sub DAS Ambesea, Sub DAS Aosole, Sub DAS Landetalo dan Sub DAS Wolasi, dengan total 
areal mencapai 66.906 Ha (BPDASHL Sampara, 2016).

Dari aspek keberadaan lahan pada DAS Laeya di Kabupaten Konawe Selatan didominasi oleh konidisi lahan agak kritis dan lahan kritis. Total luas lahan agak kritis di DAS Laeya sebesar $37.605 \mathrm{Ha}$ atau mencapai 56,21\% dari total luas DAS Laeya, dan kondisi lahan kritis mencapai $33,62 \%$ atau sebesar 22.492 Ha. Sementara itu berdasarkan sebaran Sub DAS, Sub DAS Aosole menunjukkan lahan kritis yang sangat tinggi yaitu 13,519 Ha. Kondisi tersebut dipengaruhi oleh beberapa faktor yaitu faktor manusia, faktor alam, faktor aktivitas pada lahan tersebut (BPDASHL Sampara, 2016). Olehnya itu, kajian spesifik mengenai Studi Integrasi Pertanian, Kehutanan, dan Peternakan/ Agrosilvopastural di Wilayah Daerah Aliran Sungai Laeya Kabupaten Konawe Selatan penting untuk dilaksanakan. Tujuan penelitian ini adalah untuk: (1) mengidentifikasi jenis usaha agrosilvopastural di wilayah sekitar DAS Laeya;(2) menganalisis karakteristik pelaku usaha agrosilvopastural di wilayah sekitar DAS Laeya; dan (3) menganalisis keragaan usaha agrosilvopastural di wilayah sekitar DAS Laeya.

\section{METODE PENELITIAN}

\section{Lokasi dan Waktu Kegiatan}

Lokasi yang dijadikan obyek Studi Integrasi Pertanian, Kehutanan, dan Peternakan (Agrosilvopastural) meliputi wilayah hulu dan hilir DAS Laeya Kabupaten Konawe Selatan. Sementara itu, waktu pelaksanaan penelitian dilaksanakan pada bulan Mei sampai Juli 2018.

\section{Metode Pengumpulan Data}

Dalam rangka mengumpulkan fakta empiris yang terkait dan sesuai dengan kebutuhan Studi Integrasi Pertanian, Kehutanan, dan Peternakan (Agrosilvopastural) di Wilayah DAS Laeya di Kabupaten Konawe Selatan, dilakukan pengumpulan data, yang terdiri dari pengumpulan data sekunder dan pengumpulan data primer. Pengumpulan data sekunder dilakukan dengan cara mengumpulkan data dan informasi sekunder dari berbagai instansi yang diidentifikasi memiliki keterkaitan dengan kebutuhan data dalam penelitian atau sesuai dengan daftar kebutuhan kegiatan yang dimaksud. Sementara itu, pengumpulan data primer dilakukan dengan cara wawancara dengan masyarakat yang bermukim di wilayah hulu dan hilir DAS Laeya yang berjumlah 51 rumah tangga.
Penentuan jumlah responden tersebut dilakukan secara accidental sampling.

\section{Metode Analisis Data}

Analisis Deskriptif. Analisis deskriptif digunakan untuk mendeskripsikan hasil temuan lapangan secara konvensional agar dapat memberikan gambaran secara sistematis, faktual dan akurat terhadap sasaran yang diteliti dalam kegiatan yang dimaksud. Sasaran yang dimaksud tersebut adalah; (1) identifikasi jenis usaha, dan (2) karakteristik pelaku usaha agrosilvopastural.

Analisis Pendapatan dan Kelayakan Usaha. Analisis pendapatan dan kelayakan usaha dalam kajian ini digunakan untuk menganalisis keragaan usaha agrosilvopastural di Wilayah DAS Laeya Kabupaten Konawe Selatan. Jumlah pendapatan pada beberapa jenis hasil perikanan di Kabupaten Konawe Selatan. Dalam analisis ini digunakan persamaan menurut Soekartawi (2002) sebagai berikut:

$\mathrm{Y}_{\mathrm{i}}=\mathrm{TR}_{\mathrm{i}}-\mathrm{TC}_{\mathrm{i}} ; \mathrm{TR}_{\mathrm{i}}=\mathrm{P}_{\mathrm{iQ}} \times \mathrm{Q}_{\mathrm{i}}$

$\mathrm{TCi}=\sum_{i=n}^{n}$ Pxi. Xi

Keterangan;

$\mathrm{Y}_{\mathrm{i}}=$ Pendapatan rata-rata (Rp/tahun);

$\mathrm{TR}_{\mathrm{i}}=$ Penerimaan rata-rata (Rp/tahun)

$\mathrm{P}_{\mathrm{iQ}}=$ Harga produksi rata-rata $(\mathrm{Rp} / \mathrm{kg}) ;$

$\mathrm{Q}_{\mathrm{i}}=$ Produksi rata- $(\mathrm{Kg} /$ tahun $)$

$\mathrm{TC}_{\mathrm{i}}=$ Biaya total rata-rata (Rp/tahun)

$\mathrm{Px}_{\mathrm{i}}=$ Harga pembelian faktor $(\mathrm{Rp} /$ tahun $)$

$\mathrm{X}_{\mathrm{i}}=$ Jumlah pembelian faktor produksi (unit).

Selanjutnya analisis kelayakan usaha digunakan untuk prospek suatu usaha pada beberapa hasil perikanan, melalui pendekatan analisis imbangan penerimaan dan biaya $(\mathrm{R} / \mathrm{C})$ dengan persamaan sebagai berikut:

$$
\mathrm{R} / \mathrm{C}=\mathrm{TR} / \mathrm{TC}
$$

\section{Keterangan:}

- Jika R/C > 1, usaha agrosilvopastural prospek untuk dikembangkan (menguntungkan),

- Jika R/C < 1, usaha agrosilvopastural tidak prospek untuk dikembangkan (rugi),

- Jika R/C = 1, usaha agrosilvopastural kembali pokok.

\section{HASIL PENELITIAN}

\section{Identifikasi Jenis Usaha Agrosilvopastural}

Gambaran mengenai jenis usaha agrosilvopastural di wilayah DAS Laeya Kabupaten Konawe Selatan disajikan pada Tabel 1. Hasil identifikasi lapangan menunjukkan bahwa terdapat jenis usaha pertanian, kehutanan, dan usaha peternakan yang relatif sama antara 
wilayah hulu dan wilayah hilir DAS Laeya Kabupaten Konawe Selatan.

Tabel 1. Jenis Usaha Agrosilvopastural Di Wilayah Das Laeya

\begin{tabular}{|c|c|c|c|}
\hline No & $\begin{array}{l}\text { Wilayah } \\
\text { DAS Laeya }\end{array}$ & $\begin{array}{c}\text { Jenis Usaha } \\
\text { Agrosilvopastural }\end{array}$ & $\begin{array}{l}\text { Luasan } \\
\text { (ha) }\end{array}$ \\
\hline A & Hulu & $\begin{array}{ll}\text { 1. } & \text { Padi Ladang } \\
\text { 2. } & \text { Jagung } \\
\text { 3. } & \text { Palawija } \\
\text { 4. } & \text { Jambu Mete } \\
\text { 5. } & \text { Lada } \\
\text { 6. } & \text { Jati Lokal } \\
\text { 7. } & \text { Jati Putih } \\
\text { 8. } & \text { Sapi Bali } \\
\text { 9. } & \text { Unggas Lokal } \\
\end{array}$ & $0,75-6,00$ \\
\hline B & Hilir & $\begin{array}{ll}\text { 1. } & \text { Padi Ladang } \\
\text { 2. } & \text { Padi Sawah } \\
\text { 3. } & \text { Jagung } \\
\text { 4. } & \text { Palawija } \\
\text { 5. } & \text { Buah-Buahan } \\
\text { 6. } & \text { Jambu Mete } \\
\text { 7. } & \text { Lada } \\
\text { 8. } & \text { Kelapa Sawit } \\
\text { 9. } & \text { Jati Lokal } \\
\text { 10. } & \text { Jati Putih } \\
\text { 11. } & \text { Jabon } \\
\text { 12. } & \text { Kayu Biti } \\
\text { 13. } & \text { Sapi Bali } \\
\text { 14. } & \text { Unggas Lokal } \\
\text { 15. } & \text { Kambing }\end{array}$ & $0,75-6,00$ \\
\hline
\end{tabular}

Sumber: Data Primer, 2018

Hasil penelitian menunjukkan bahwa pada wilayah hulu DAS Laeya jenis usaha agrosilvopastural antara lain; padi ladang, jagung, tanaman palawija, jambu mete, lada, jati lokal, jati putih, sapi bali, dan unggas lokal. Sementara itu, wilayah hilir DAS Laeya jenis usaha agrosilvopastural antara lain; padi ladang, padi sawah, jagung, palawija, buah-buahan, jambu mete, lada, kelapa sawit, jati lokal, jati putih, jabon, kayu biti, sapi bali, unggas lokal, dan ternak kambing. Hal ini sejalan dengan hasil penelitian Zega et al. (2012) yang menyatakan bahwa Jenis-jenis produk agroforestry yang dimanfaatkan oleh masyarakat Desa Sitaratoit dan Desa Lobulayan adalah salak, alpukat, aren, cabai, cengkeh, durian, jagung, kacang tanah, kelapa,kemiri, kopi, kunyit, mangga, petai, pinang, pisang, serai, ubi kayu, dan kayu bakar. Berdasarkan Tabel 1, maka jenis usaha agrosilvopastural dalam kajian ini dikelompokkan sebagai berikut:

a. Tanaman pangan, palawija, dan hortikultura (semusim), yang terdiri dari; padi ladang, padi sawah, jagung, cabai, serta jenis sayursayuran dan buah-buahan b. Tanaman perkebunan (tahunan) yang terdiri dari; jambu mete, lada, dan kelapa sawit

c. Tanaman kehutanan yang terdiri dari; jati lokal, jati putih, jabon, dan kayu biti

d. Peternakan yang terdiri dari; sapi bali, unggas lokal, dan kambing

De Foresta dan Michon (1997), Sardjono et al. (2003) menyatakan bahwa sistem agroforestry yang mengkombinasikan komponen kehutanan (tanaman berkayu atau woody plants) dengan komponen pertanian (tanaman non-kayu) disebut sebagai sistem agrisilvikultur.

\section{Karakteristik Pelaku Usaha Agrosilvopastural}

Umur; Salah satu faktor yang dapat mempengaruhi kemampuan seseorang dalam berpikir adalah umur. Umur pelaku usaha sangat mempengaruhi berhasil tidaknya suatu kegiatan usaha, karena umur dapat mempengaruhi produktivitas kerja dan kemampuan pelaku usaha dalam mengelola usahanya. Pelaku usaha yang mempunyai umur lebih muda biasanya lebih agresif dalam mengambil keputusan dan lebih mau menerima inovasi baru serta lebih berani dalam mengambil risiko (Soehardjo dan Patong, 1984). Gambaran mengenai umur pelaku usaha agrosilvopastural di lokasi penelitian dapat dilihat pada Tabel 2.

Tabel 2. Umur Pelaku Usaha Agrosilvopastural di Wilayah DAS Laeya Kabupaten Konawe Selatan, Tahun 2018

\begin{tabular}{|c|c|c|c|c|}
\hline \multirow{2}{*}{ No } & \multirow{2}{*}{$\begin{array}{l}\text { Kelompok } \\
\text { Pelaku Usaha }\end{array}$} & \multicolumn{3}{|c|}{ Umur (Tahun) } \\
\hline & & Tertinggi & Terendah & Rata-rata \\
\hline 1 & $\begin{array}{l}\text { Wilayah Hulu } \\
\text { DAS Laeya }\end{array}$ & 63 & 29 & 48,5 \\
\hline 2 & $\begin{array}{l}\text { Wilayah Hilir } \\
\text { DAS Laeya }\end{array}$ & 59 & 29 & 44,5 \\
\hline
\end{tabular}

Sumber: Analisis Data Primer, 2018

Berdasarkan hasil penelitian diperoleh informasi bahwa kisaran umur pelaku usaha agrosilvopastural bervariasi, yaitu berkisar antara 29-63 tahun untuk kelompok pelaku usaha agrosilvopastural wilayah hulu DAS Laeya dan berkisar antara 29-59 tahun untuk kelompok pelaku usaha agrosilvopastural wilayah hilir DAS Laeya. Selain itu pada Tabel 2 juga menunjukan bahwa rata-rata umur pelaku usaha agrosilvopastural wilayah hilir DAS Laeya lebih produktif yaitu rata-rata sebesar 44,5 tahun, sedangkan wilayah hulu DAS Laeya rata-rata berumur 48,5 tahun. Fenomena tersebut mengindikasikan bahwa pelaku usaha agrosilvopastural wilayah hilir DAS Laeya di Kabupaten Konawe Selatan akan relatif lebih 
produktif dibandingkan wilayah hilir DAS Laeya dalam mengelola usahataninya.

Pendidikan; Hasil penelitian menunjukkan bahwa pendidikan formal yang pernah dilalui pelaku usaha agrosilvopastural wilayah hulu DAS Laeya berkisar antara 3-12 tahun, sedangkan pada wilayah hilir DAS Laeya berkisar antara 2-12 tahun.

\begin{tabular}{|c|c|c|c|c|}
\hline & $\begin{array}{l}\text { Tingkat } \\
\text { agrosilvopas } \\
\text { Kabupaten }\end{array}$ & $\begin{array}{l}\text { pendidikan } \\
\text { ural di v } \\
\text { onawe Sel }\end{array}$ & $\begin{array}{l}\text { pelaku } \\
\text { ayah DA } \\
\text { n, tahun } 2\end{array}$ & $\begin{array}{l}\text { usaha } \\
\text { Laeya } \\
8\end{array}$ \\
\hline \multirow[b]{2}{*}{ No } & \multirow[b]{2}{*}{$\begin{array}{l}\text { Kelompok } \\
\text { Pelaku usaha }\end{array}$} & \multicolumn{3}{|c|}{ Pendidikan (Tahun) } \\
\hline & & Tertinggi & Terendah & $\begin{array}{l}\text { Rata- } \\
\text { Rata }\end{array}$ \\
\hline 1 & $\begin{array}{l}\text { Wilayah Hulu } \\
\text { DAS Laeya }\end{array}$ & 12 & 3 & 8,4 \\
\hline 2 & $\begin{array}{l}\text { Wilayah } \\
\text { Hilir DAS } \\
\text { Laeya }\end{array}$ & 12 & 2 & 8,8 \\
\hline
\end{tabular}

Sumber: Analisis Data Primer, 2018

Tabel 3 menunjukkan bahwa tingkat pendidikan tertinggi yang pernah dilalui oleh pelaku usaha agrosilvopastural pada kedua kelompok adalah berpendidikan SMA, sedangkan pendidikan terendah adalah tidak tamat SD. Kondisi ini memberikan gambaran bahwa ratarata pelaku usaha agrosilvopastural di wilayah Hulu dan Hilir DAS Laeya Kabupaten Konawe Selatan mempunyai tingkat pendidikan yang kurang memadai, dimana rata-rata tingkat pendidikan formal yang pernah ditempuh adalah tidak tamat SMP atau selama 8,8 tahun dan 8,8 tahun. Kondisi tersebut tentunya sangat mempengaruhi cara kerja dan pola pikir pelaku usaha dalam mengelola usahanya. Hal ini sesuai dengan pendapat Soehardjo dan Patong (1984) yang menyatakan bahwa tingkat pendidikan yang relatif tinggi dan berumur lebih muda, menyebabkan pelaku usaha cenderung lebih dinamis yang tercermin melalui cara kerja, cara berpikir dan mudah tidaknya dalam menerima inovasi serta teknologi baru, yang pada akhirnya dapat berpengaruh pada peningkatan nilai tambah dari usaha yang dikelolanya.

Pengalaman Berusaha; Pengalaman berusaha dari seorang pelaku usaha dapat diketahui melalui lamanya seorang dalam melakukan usahatani. Dalam penelitian ini diperoleh informasi bahwa rata-rata pelaku usaha agrosilvopastural di Wilyaha DAS Laeya Kabupaten Konawe Selatan dalam melakukan usahanya adalah merupakan usaha yang turun temurun. Olehnya itu, sebagian besar pengetahuan ataupun pengalaman pelaku usaha diperoleh berdasarkan kebiasaan atau perilaku dari orang tua. Pengalaman pelaku usaha agrosilvopastural di wilayah DAS Laeya Kabupaten Konawe Selatan disajikan pada Tabel 4.

Tabel 4. Pengalaman pelaku usaha agrosilvopastural di wilayah DAS Laeya Kabupaten Konawe Selatan, tahun 2018

\begin{tabular}{clccc}
\hline \multirow{2}{*}{ No } & $\begin{array}{l}\text { Kelompok } \\
\text { Pelaku } \\
\text { Usaha }\end{array}$ & \multicolumn{3}{c}{$\begin{array}{c}\text { Pengalaman Berusahatani } \\
\text { (Tahun) }\end{array}$} \\
\cline { 3 - 5 } & Tertinggi & Terendah & $\begin{array}{c}\text { Rata- } \\
\text { Rata }\end{array}$ \\
\hline 1 & $\begin{array}{l}\text { Wilayah } \\
\text { Hulu DAS }\end{array}$ & 43 & 3 & 21,4 \\
& $\begin{array}{l}\text { Laeya } \\
\text { Wilayah } \\
\text { Hilir DAS } \\
\text { Laeya }\end{array}$ & 30 & 3 & 13,5 \\
\hline
\end{tabular}

Sumber: Analisis Data Primer, 2018

Hasil penelitian menunjukkan bahwa pengalaman pelaku usaha agrosilvopastural dalam berusahatani bervariasi berkisar antara 3 43 tahun dengan rata-rata pengalaman selama 21,4 tahun untuk kelompok pelaku usaha wilayah hulu DAS Laeya dan selama 13,5 tahun untuk kelompok pelaku usaha wilayah hilir DAS Laeya. Jika dilihat dari segi pengalaman berusahatani, maka dapat dikatakan bahwa pelaku usaha agrosilvopastural pada kedua kelompok tersebut akan memiliki peluang yang besar dalam pencapaian keberhasilan dalam melakukan kegiatan usahataninya.

Jumlah Tanggungan Keluarga; Hasil penelitian menunjukkan bahwa jumlah tanggungan keluarga pelaku usaha agrosilvopastural pada kedua kelompok agrosilvopastural masing-masing berkisar antara 2-6 orang dan 2-13 orang, dengan rata-rata jumlah tanggungan keluarga adalah 3 dan 4 orang. Jumlah tanggungan keluarga pelaku usaha agrosilvopastural pada wilayah DAS Laeya di Kabupaten Konawe Selatan disajikan pada Tabel 5.

Tabel 5 menunjukkan bahwa pada umumnya pelaku usaha agrosilvopastural yang berada di Wilayah DAS Laeya Kabupaten Konawe Selatan dalam hal jumlah tanggungan keluarga dikategorikan dalam golongan yang sedang (rata-rata 3 dan 4 orang). Pernyataan ini sesuai dengan pendapat Tohir (1991) yang menyatakan bahwa jumlah tanggungan keluarga dibagi dalam 3 golongan, yakni keluarga kecil (< 4 orang), keluarga sedang (4 - 6 orang) dan keluarga besar (> 6 orang). 
Tabel 5. Tanggungan Keluarga Pelaku Usaha Agrosilvopastural di Wilayah DAS Laeya Kabupaten Konawe Selatan, Tahun 2018

\begin{tabular}{clccc}
\hline \multirow{2}{*}{ No } & $\begin{array}{l}\text { Kelompok } \\
\text { Pelaku } \\
\text { Usaha }\end{array}$ & \multicolumn{3}{c}{ Tanggungan Keluarga (Orang) } \\
\cline { 2 - 5 } 1 & $\begin{array}{l}\text { Wilayah } \\
\text { Hulu DAS } \\
\text { Laeya }\end{array}$ & 6 & 2 & 3 \\
2 & $\begin{array}{l}\text { Wilayah } \\
\text { Hilir DAS } \\
\text { Laeya }\end{array}$ & 13 & 2 & 4 \\
\hline
\end{tabular}

Sumber: Analisis Data Primer, 2018

\section{Keragaan Usaha Agrosilvopastural}

Status Kepemilikan dan Luas Lahan; Hasil penelitian menunjukkan bahwa seluruh pelaku usaha Agrosilvopastural yang berada di lokasi penelitian memiliki lahan ushatani dengan status kepemilikan hak milik, baik pada kelompok pelaku usaha Agrosilvopastural Wilayah Hulu DAS Laeya maupun Wilayah Hilir DAS Laeya. Hal ini tentunya akan menguntungkan pelaku usaha karena tidak lagi mengeluarkan biaya sewa lahan. Sementara itu, luas lahan mempunyai kedudukan yang sangat penting dalam suatu usahatani. Hal ini terbukti dengan besarnya balas jasa yang diberikan oleh tanah dibandingkan oleh faktor produksi lainnya. Mubyarto (1994) mengatakan bahwa tanah merupakan salah satu faktor produksi dan merupakan pabriknya hasil-hasil pertanian, yakni tempat dimana produksi berjalan dan darimana produksi keluar. Hasil penelitian menunjukkan bahwa luas lahan pelaku usaha Agrosilvopastural pada kelompok pelaku usaha Wilayah Hulu DAS Laeya di Kabupaten Konawe Selatan lebih luas dibandingkan dengan kelompok Wilayah Hilir DAS Laeya yakni berkisar antara 0,75-6 hektar dan 1-6 hektar dengan rata-rata 2,6 hektar dan 2,5. Gambaran mengenai besarnya luas lahan pelaku usaha Agrosilvopastural di lokasi penelitian disajikan pada Tabel 6 .

Tabel 6 memberikan gambaran bahwa dari segi rata-rata kepemiikan lahan, pelaku usaha Agrosilvopastural pada wilayah DAS Laeya di Kabupaten Konawe Selatan memiliki kategori lahan yang luas. Hal ini sesuai dengan pendapat Hernanto (1996) yang menyatakan bahwa luas lahan pertanian dikategorikan dalam 3 (tiga) kelompok, yaitu lahan sempit (memiliki luasan < 0,5 hektar), lahan sedang (memiliki luasan 0,5 2,0 hektar) dan kategori lahan luas (memiliki luasan > 2,0 hektar). Selain itu, luas lahan yang sedang akan berimplikasi pada produksi dan produktivitas yang akan dihasilkan (Soekartawi, 2002).

Tabel 6. Luas Lahan Usaha tani Agrosilvopastural di Wilayah DAS Laeya Kabupaten Konawe Selatan, Tahun 2018

\begin{tabular}{|c|c|c|c|c|}
\hline \multirow[b]{2}{*}{ No } & \multirow{2}{*}{$\begin{array}{l}\text { Kelompok } \\
\text { Pelaku } \\
\text { Usaha }\end{array}$} & \multicolumn{3}{|c|}{ Luas Lahan (Hektar) } \\
\hline & & Tertinggi & Terendah & $\begin{array}{l}\text { Rata- } \\
\text { Rata }\end{array}$ \\
\hline 1 & $\begin{array}{l}\text { Wilayah } \\
\text { Hulu DAS } \\
\text { Laeya }\end{array}$ & 6 & 0,75 & 2,6 \\
\hline 2 & $\begin{array}{l}\text { Wilayah } \\
\text { Hilir DAS } \\
\text { Laeya }\end{array}$ & 6 & 1 & 2,5 \\
\hline
\end{tabular}

Sumber: Analisis Data Primer, 2018

Biaya Produksi Usahatani Agrosivopastural; Biaya produksi yang dimaksud dalam penelitian ini adalah total korbanan yang digunakan petani dalam melakukan usahatani selama satu tahun. Berdasarkan hasil penelitian diketahui bahwa petani yang Wilayah Hulu dan Hilir DAS Laeya menerapkan sistem pertanian agrosilvopastural. Sistem pertanian agrosilvopastural merupakan adalah pengkombinasian komponen tanaman berkayu (kehutanan) dengan pertanian (semusim) dan sekaligus peternakan pada unit manajemen lahan yang sama Hal ini dilakukan agar biaya yang keluarkan dapat digunakan secara efesien. Jenis komoditi agrosivopastural yang diusahakan oleh petani responden di lokasi penelitian meliputi; (1) Tanaman pangan, palawija, dan hortikultura (semusim), yang terdiri dari; padi ladang, padi sawah, jagung, cabai, serta jenis sayur-sayuran dan buah-buahan. (2) Tanaman perkebunan (tahunan) yang terdiri dari; jambu mete, lada, dan kelapa sawit,. (3) Tanaman kehutanan yang terdiri dari; jati lokal, jati putih, jabon, dan kayu biti. serta (4) Peternakan yang terdiri dari; sapi bali, unggas lokal, dan kambing. Olehnya itu dalam perhitungan analisis biaya dalam proses produksi pada penelitian ini digunkan secara bersamaan (joint cost). Selain itu, dalam perhitungan analisis biaya dalam kajian ini menggunakan jumlah petani contoh sebanyak 51 responden rumahtangga yang terdistribusi pada Wilayah Hulu dan Hiir DAS Laeya.

Hasil penelitian diperoleh informasi bahwa komponen biaya produksi yang digunakan petani responden pada usahatani agrosivopastural di Wilayah DAS Laeya terdiri dari komponen biaya variabel dan biaya tetap. Biaya variabel yang dimaksud dalam penelitian ini adalah ratarata nilai pembelian benih, 
Tabel 7. Biaya variabel usahatani agrosilvopastural di wilayah DAS Laeya Kabupaten Konawe Selatan, tahun 2018

\begin{tabular}{cccccc}
\hline \multirow{2}{*}{ No } & \multirow{2}{*}{ Kelompok Pelaku Usaha } & \multicolumn{2}{c}{ Biaya Variabel (Rp/Hektar/Tahun) } & \multirow{2}{*}{$\begin{array}{c}\text { Jumlah Resp. } \\
\text { (Orang) }\end{array}$} \\
\cline { 3 - 5 } & & Terendah & Tertinggi & Rata-Rata & \\
\hline 1 & Wilayah Hilir DAS Laeya & 388.000 & 23.750 .000 & 4.092 .917 & 25 \\
2 & Wilayah Hulu DAS Laeya & 976.000 & 23.350 .000 & 6.980 .760 & 26 \\
\hline
\end{tabular}

Sumber: Analisis Data Primer, 2018

Tabel 8. Biaya tetap usahatani agrosilvopastural di wilayah DAS Laeya Kabupaten Konawe Selatan, tahun 2018

\begin{tabular}{|c|c|c|c|c|c|}
\hline \multirow{2}{*}{ No } & \multirow{2}{*}{ Kelompok Pelaku Usaha } & \multicolumn{3}{|c|}{ Biaya Tetap (Rp/Hektar/Tahun) } & \multirow{2}{*}{$\begin{array}{c}\text { Jumlah Resp. } \\
\text { (Orang) }\end{array}$} \\
\hline & & Terendah & Tertinggi & Rata-Rata & \\
\hline 1 & Wilayah Hilir DAS Laeya & 218.333 & 44.833 .333 & 6.799 .091 & 25 \\
\hline 2 & Wilayah Hulu DAS Laeya & 81.667 & 27.750 .000 & 3.649 .421 & 26 \\
\hline
\end{tabular}

Sumber: Analisis Data Primer, 2018

Tabel 9. Penerimaan usahatani agrosilvopastural di wilayah DAS Laeya Kabupaten Konawe Selatan, tahun 2018

\begin{tabular}{|c|c|c|c|c|c|}
\hline \multirow{2}{*}{ No } & \multirow{2}{*}{ Kelompok Pelaku Usaha } & \multicolumn{3}{|c|}{ Jumlah Penerimaan (Rp/Hektar/Tahun) } & \multirow{2}{*}{$\begin{array}{c}\text { Jumlah Resp. } \\
\text { (Orang) }\end{array}$} \\
\hline & & Terendah & Tertinggi & Rata-Rata & \\
\hline 1 & Wilayah Hilir DAS Laeya & 9.500 .000 & 421.125 .000 & 70.273 .362 & 25 \\
\hline 2 & Wilayah Hulu DAS Laeya & 2.000 .000 & 263.750 .000 & 45.826 .767 & 26 \\
\hline
\end{tabular}

Sumber: Analisis Data Primer, 2018

pupuk, dan pestisida pada usaha tani agrosivopastural dalam satu tahun terakhir yang terbagi dalam tiga musim tanam.

Tabel 7 menunjukkan bahwa besarnya rata-rata biaya variabel usahatani agrosivopastural pada wilayah penelitian. Biaya variabel di Wilayah Hulu DAS Laeya berkisar antara Rp 976.000,- sampai Rp 23.350.000,- per hektar per tahun, di Wilayah Hilir DAS Laeya antara Rp 388.000,- sampai Rp 23.750.000,- per hektar per tahun. Berdasarkan gambaran tersebut, maka dapat diketahui bahwa di Wilayah Hilir DAS Laeya merupakan daerah yang memiliki kisaran biaya variabel terkecil dibandingkan dengan Wilayah Hulu DAS Laeya. Sementara itu, secara keseluruhan besarnya ratarata biaya variabel usahatani agrosivopastural di Wilayah DAS Laeya berkisar antara Rp 4.092.917,- sampai Rp 6.980.760,-- per hektar per tahun.

Selanjutnya, biaya tetap (fixed cost) yang dikeluarkan pada usahatani agrosivopastural di desa terpilih di Wilayah DAS Laeya ini disajikan pada Tabel 8 yang menunjukkan bahwa besarnya rata-rata biaya tetap usahatani agrosivopastural pada Wilayah DAS Laeya bervariasi. Biaya tetap di Wilayah Hilir DAS Laeya berkisar antara Rp 218.333,- sampai Rp 44.833.333,-- per hektar per tahun dan di Wilayah Hulu DAS Laeya berkisar antara Rp 81.667,-- sampai Rp 27.750.000,- per hektar per tahun.

Berdasarkan gambaran tersebut, maka dapat diketahu bahwa di Wilayah Hulu DAS Laeya juga merupakan daerah yang memiliki kisaran biaya tetap terkecil dibandingkan dengan Wilayah Hilir DAS Laeya Sementara itu, secara keseluruhan besarnya rata-rata biaya tetap usahatani agrosivopastural di Wilayah DAS Laeya berkisar antara Rp 3.649.421,- sampai Rp 6.799.091,- per tahun.

Penerimaan Usahatani Agrosivopastural; Penerimaan yang dimaksud dalam penelitian ini adalah rata-rata besarnya pendapatan kotor dari usaha usahatani pada beberapa tanaman agrosivopastural, yang diperoleh dari hasil perkalian antara jumlah produksi yang diperoleh dengan harga jual produksi. Ringkasan jumlah penerimaan pada usahatani agrosivopastural di Wilayah DAS Laeya ini disajikan pada Tabel 9.

Tabel 9 menunjukkan bahwa besarnya rata-rata penerimaan usahatani agrosivopastural di Wilayah DAS Laeya bervariasi. Penerimaan di Wilayah Hilir DAS Laeya berkisar antara Rp 9.500.000,- sampai Rp 421.125.000,- per hektar per tahun dan di Wilayah Hulu DAS Laeya berkisar antara Rp 2.000.000,- sampai Rp 263.750.000,-- per hektar per tahun. Berdasarkan gambaran tersebut, maka dapat diketahu bahwa di Wilayah Hilir DAS Laeya merupakan daerah 
yang memiliki kisaran penerimaan terbesar dibandingkan dengan di Wilayah Hulu DAS Laeya. Sementara itu, secara keseluruhan besarnya rata-rata penerimaan usahatani agrosivopastural di Wilayah DAS Laeya berkisar antara Rp 45.826.767,-- sampai Rp 70.273.362,-per hektar per tahun.

Pendapatan Usahatani Agrosivopastural; Hasil analisis menunjukkan bahwa aktivitas usahatani agrosivopastural di Wilayah DAS Laeya memperoleh pendapatan atau dengan kata lain memperoleh keuntungan potensial dari segi ekonomi. Gambaran tersebut dapat dilihat dari jumlah rata-rata penerimaan yang mampu menutupi seluruh rata-rata total biaya produksi. Ringkasan jumlah pendapatan pada usahatani agrosivopastural di desa terpilih di Wilayah DAS Laeya ini disajikan pada Gambar 1.

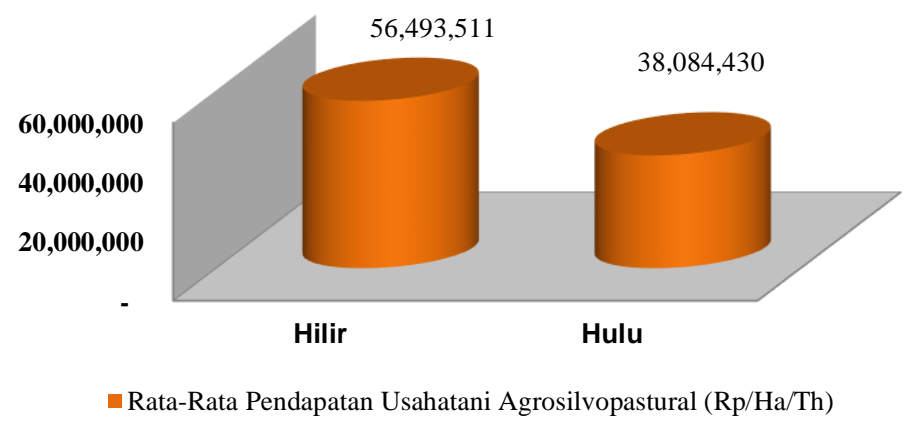

Gambar 1. Rata-Rata Jumlah Pendapatan Usahatani Agrosilvopastural di Wilayah DAS Laeya Kabupaten Konawe Selatan, Tahun 2018

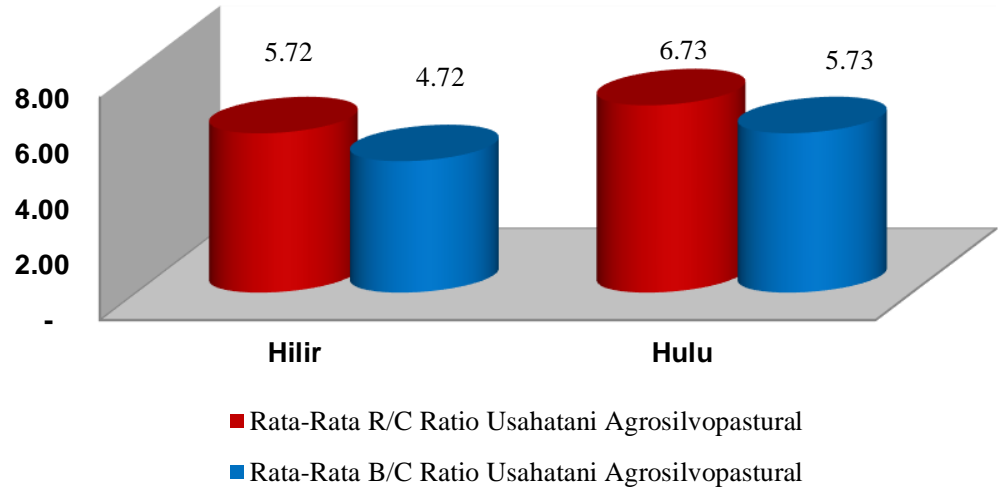

Gambar 2. Rata-Rata Kelayakan Usaha Agrosilvopastural di Wilayah DAS Laeya Kabupaten Konawe Selatan, Tahun 2018

Hasil penelitian menunjukkan bahwa rata-rata jumlah pendapatan di Wilayah Hilir DAS Laeya lebih tinggi dibandingkan dengan di Wilayah Hulu DAS Laeya, yakni sebesar Rp 56.493.511,- per hektar per tahun. Jumlah ratarata pendapatan petani responden di Wilayah Hulu DAS Laeya sebesar Rp 38.084.430,- per hektar per tahun. Perbedaan jumlah pendapatan tersebut, tentunya dipengaruhi oleh besar kecilnya jumlah produksi dan biaya produksi yang dikeluarkan dari masing-masing respoden di wilayah DAS Laeya. Olehnya itu, berdasarkan hasil analisis tersebut dapat dikatakan bahwa petani agrosivopastural di Wilayah Hilir DAS Laeya lebih efisien dalam mengelola usahataninya dibandingkan di Wilayah Hulu DAS Laeya.

Analisis Kelayakan Usaha Tanaman Agrosivopastural. Dalam Kajian ini, kelayakan usaha pada pengembangan tanaman agrosivopastural diproksi berdasarkan pendekatan return cost ratio (R/C), atau dikenal sebagai perbandingan (nisbah) antara penerimaan dan biaya. Selain pendekatan $\mathrm{R} / \mathrm{C}$ ratio juga digunakan pedekatan $\mathrm{B} / \mathrm{C}$ ratio, yakni nisbah antara pendapatan dan biaya. 
Komponen variabel yang digunakan untuk mengukur kelayakan usaha tersbut adalah ratarata total biaya produksi (biaya variabel dan biaya tetap) serta rata-rata total penerimaan dari usahatani agrosivopastural. Deskripsi mengenai kelayakan $(\mathrm{R} / \mathrm{C}$ ratio dan $\mathrm{B} / \mathrm{C}$ ratio) pada usaha agrosivopastural di Wilayah DAS Laeya disajikan dalam Gambar 2.

Gambar 2 menunjukkan bahwa usahatani agrosivopastural pada petani responden di seluruh wilayah DAS Laeya layak untuk dikembangkan. Hal ini dapat dilihat dari besarnya nilai R/C-ratio lebih besar 1 (R/C > 1). Nilai rata-rata $\mathrm{R} / \mathrm{C}$ ratio di Wilayah Hilir DAS Laeya sebesar 5,72 dan di Wilayah Hulu DAS Laeya sebesar 6,73. Hal tersebut menunjukkan bahwa setiap satu rupiah biaya yang dikeluarkan pada usahatani agrosivopastural di masing-masing wlayah, akan menghasilkan penerimaan potensial masingmasing sebesar $\mathrm{Rp} 5,72$ sampai $\mathrm{Rp} 6,73$. B/C ratio digunakan untuk menentukan tingkat pendapatan atau efisiensi biaya yang telah dikeluarkan dalam kegiatan usahatani agrosivopastural. Pada penelitian ini, B/C ratio merupakan nilai pendapatan bersih dari usahatani agrosivopastural yang menunjukkan berapa kali lipat pendapatan bersih yang bisa diperoleh dari setiap rupiah yang dikorbankan. Seperti halnya pada $\mathrm{R} / \mathrm{C}$ ratio, hasil analisis pada $\mathrm{B} / \mathrm{C}$ ratio juga menunjukkan bahwa nilai yang diperoleh di masing-masing wilayah DAS juga lebih besar dari $1(\mathrm{~B} / \mathrm{C}>1)$. Nilai $\mathrm{B} / \mathrm{C}$ ratio di di Wilayah Hilir DAS Laeya sebesar 4,72 dan di Wilayah Hulu DAS Laeya sebesar 5,73. Hal tersebut menunjukkan bahwa setiap satu rupiah biaya yang dikeluarkan pada usahatani agrosivopastural di wilayah DAS Laeya, akan menghasilkan pendapatan masingmasing sebesar 4,72 sampai 5,73 kali lipat.

\section{KESIMPULAN}

Jenis usaha agrosilvopastural di wilayah sekitar DAS Laeya Kabupaten Konawe Selatan meliputi; (a) Tanaman pangan, palawija, dan hortikultura (semusim), yang terdiri dari; padi ladang, padi sawah, jagung, cabai, serta jenis sayur-sayuran dan buah-buahan, (b) Tanaman perkebunan (tahunan) yang terdiri dari; jambu mete, lada, dan kelapa sawit, (c) Tanaman kehutanan yang terdiri dari; jati lokal, jati putih, jabon, dan kayu biti, dan (d) Peternakan yang terdiri dari; sapi bali, unggas lokal, dan kambing. Berdasarkan hasil analisis $\mathrm{R} / \mathrm{C}$ ratio dan $\mathrm{B} / \mathrm{C}$ ratio, bahwa usaha agrosilvopastural di wilayah hulu dan hilir DAS Laeya Kabupaten Konawe Selatan layak untuk dijadikan sebagai objek pengembangan usaha agrosivopastural, dengan rata-rata nilai $\mathrm{R} / \mathrm{C}$ ratio sebesar 4,02 dan $\mathrm{B} / \mathrm{C}$ ratio sebesar 3,02. Olehnya itu, untuk mendukung program pengelolaan DAS perlu adanya program penanaman pohon pada lahanlahan kritis baik pada hulu maupun hilir DAS Laeya, dengan jenis tanaman seperti; Jati Lokal (Tectona grandis), Jabon (Anthocepalus cadamba), Meranti (Shore sp), Kemiri (Aleurites molucua), dan Mahoni (Swictenia sp) terutama pada titik-titik rawan longsor dengan memperhatikan kondisi kontur dan kemiringan lahan yang dapat diintegrasikan dengan usaha peternakan.

\section{DAFTAR PUSTAKA}

Atmojo, S.W. 2017. Pertanian Organik, Integrasi ternak dan Tanaman. Solo Pos, 7 Maret.

BPDASHL Sampara. 2016. Laporan Monitoring dan Evaluasi Pengelolaan Daerah Aliran Sungai Laeya. Kementerian Lingkungan Hidup dan Kehutanan, Direktorat Jenderal Bina Pengendalian DAS dan Hutan Lindung, Balai Pengelolaan DAS dan Hutan Lindung Sampara. Kendari.

De Foresta, H, A. Kusworo, G. Michon, \& W.A. Djatmiko. 2000. Ketika Kebun Berupa Hutan: Agroforest Khas Indonesia, Sebuah Sumbangan Masyarakat. ICRAF. Bogor.

Hairiah K., S.R. Utami, D. Suprayogo, Widianto, S.M. Sitompul, Sunaryo, B. Lusiana, R. Mulia, M. Van noordwijk, \& G. Cadish. 2000. Agroforestry on Acid Soils in Humid Tropics: Managing TreeSoil-Crop Interactions. ICRAF. Bogor.

Hernanto, F. 1996. Ilmu Usahatani. Penebar Swadaya. Jakarta.

Sabarnurdin \& M. Sambas. 2002. Agroforestry: Konsep, Prospek dan Tantangan. Presentasi Workshop Agroforestry 2002, Fakultas Kehutanan Universitas Gadjah Mada. Yogyakarta.

Sardjono, M.A., T. Djogo, H.S. Arifin, \& N. Wijayanto. 2003. Klasifikasi dan Pola Kombinasi Komponen Agroforestri. 
World Agroforestry Centre (ICRAF). Bogor.

Soeharjo, A. \& D. Patong. 1984. Sendi-sendi Pokok Usahatani. Universitas Hasanuddin. Ujung Pandang.

Soekartawi. 2002. Prinsip Dasar Manajemen Pemasaran Hasil-Hasil Pertanian; Teori dan Aplikasinya. Raja Grafindo Persada. Jakarta.

Tohir, K.A. 1991. Seuntai Pengetahuan Usahatani Indonesia. Rineka Cipta. Jakarta.

Zega, S.B., A. Purwoko, \& T. Matrial. 2012. Analisis Pengelolaan Agroforestry dan Kontribusinya terhadap Perekonomian Masyarakat. Program Studi Kehutanan, Fakultas Pertanian, Universitas Sumatera Utara. 